\title{
Circumpolar phylogeography of the northern pike (Esox lucius) and its relationship to the Amur pike (E. reichertii)
}

Anna Skog ${ }^{1,2}$, L Asbjørn Vøllestad' ${ }^{1}$ Nils Chr Stenseth ${ }^{1}$, Alexander Kasumyan ${ }^{3}$ and Kjetill S Jakobsen ${ }^{\text {** }}$

\begin{abstract}
Background: Freshwater fishes of the genus Esox are found throughout the Holarctic region. The northern pike (E. lucius) has a circumpolar distribution whereas the assumed sister species the Amur pike (E. reichertii) is only found in the Amur region. The genetic structure and post-glacial dispersal of these species are not well known. Here, we use sequence variation at two mitochondrial DNA regions (cytb and D-loop) to investigate the phylogeography, infer location of glacial refugia and investigate the time of divergence and potential demographic expansion of the various clades detected.

Results: The two species did not share haplotypes implying long-term isolation with no gene flow, and divergence of the taxa were estimated at 4.55 Myr. The northern pike mtDNA haplotypes revealed three main lineages. One of the northern pike mtDNA lineages was found throughout the entire Holarctic region suggesting transcontinental dispersal from a single refugium. The three lineages exhibited a star phylogeny, indicating population expansion following isolation in separate glacial refugia. Estimated time of divergence of these lineages was $0.18-0.26 \mathrm{Myr}$.

Conclusions: The precise location of the glacial refugia is uncertain, but our data suggests an Asian origin. The expansion of the circumpolar lineage is estimated to be around the end of the second glacial, implying that the current distribution is due to a recent recolonization from an east-Asian refugium. All three northern pike mtDNA lineages occurred sympatrically in Europe, possibly due to secondary contact. Two of the lineages probably originated from different European refugia, one in the Danube-region and one in Western Europe, the latter seems to be the primary source for recolonization of northern Europe.
\end{abstract}

Keywords: cyt b, D-loop, Glacial refugia, Phylogeny

\section{Background}

Present-day distribution of temperate species of plants and animals are strongly influenced by geological and climatic processes such as glacial cycles. During glaciation periods populations were displaced and population size reduced, and as a consequence genetic diversity was lost $[1,2]$. During interglacial periods aquatic species such as freshwater fishes had access to large lakes formed by meltwater, providing a diversity of dispersal opportunities. There are a number of phylogeographic studies investigating the geographic distribution of genealogical lineages of

\footnotetext{
*Correspondence: k.s.jakobsen@ibv.uio.no

${ }^{1}$ Centre for Ecological and Evolutionary Synthesis (CEES), Department of Biosciences, University of Oslo, P. O. Box 1066 Blindern, N-0316 Oslo, Norway Full list of author information is available at the end of the article
}

freshwater fish, but patterns differ between species [3], and there are many potential biases.

Freshwater fishes of the genus Esox are found throughout the Holarctic region. The northern pike (E. lucius) is the only species within the genus with a circumpolar distribution, whereas E. americanus, E. masquinongy and $E$. niger are only found in North America and two species only in Eurasia (E. reichertii, and E. cisalpinus (synonymous with E. flaviae)) [4-6]. The geographic origin of the genus Esox is unclear. The relatively higher number of species in North America, together with fossil evidence [7], has led to the suggestion that the genus originated on this continent [8].

While northern pike is one of the freshwater fish species with the widest Holarctic distribution range, the closely related Amur pike (E. reichertii) $[9,10]$ has a narrow 
distribution essentially being restricted to the Amur River basin in northeastern Asia. Some recent genetic evidence suggests that the northern pike originated in North American subsequently dispersing to Eurasia over the Bering land bridge [8]. This is contrary to what has been suggested earlier [11]. Further, studies indicate that North American northern pike populations have less genetic diversity and structure than the European populations [8,12-19]. Lack of genetic diversity and structure are signs often associated with recently colonized regions, while more variability and genetic structuring are seen in populations that have been existing for longer periods of time [20]. During the different glacial periods Holarctic freshwater fishes survived in a number of geographically separated refugia, and this isolation and the subsequent dispersal from these refugia have been important for shaping the intraspecific genetic variability currently seen for many freshwater fish species in the Holartic [1,3]. Generally, the geographic distribution of a species and the association with distinct phylogeographic groups (clades) are useful data for identifying glacial refugia [21-23].

Here, we assess the level and geographic distribution of genetic variation of the northern and the Amur pike. Amur pike has so far only been investigated in context of higher level phylogeny $[9,10]$. Maes et al. [24] have suggested, on the basis of short fragments of mitochondrial DNA, that the northern pike experienced a recent expansion across the Holarctic from a single refugium. The geographic location of this refugium could not be inferred. A later study [25] found more structuring (in the distribution of hapotypes) based on a longer mitochondrial DNA fragment, implying that larger fragments are needed to test this hypothesis. In this study, we used two mitochondrial DNA markers, a $1133 \mathrm{bp}$ sequence of the cytochrome $b$ (cyt $b$ ) region and a 443 bp sequence of the D-loop, to evaluate the origin and dispersal of northern pike and Amur pike using a circumpolar dataset for a northern pike.

\section{Results}

\section{Mitochondrial diversity in northern and Amur pike}

We obtained samples from 24 northern pike populations representing a total of 12 drainages across the Holarctic, and three Amur pike populations from the Amur River (sampling information and GenBank accession numbers are provided in Additional file 1). Details on diversity is given in Additional file 2, but is summarized here. The final mtDNA alignments included 443 bp of the D-loop region, and $1133 \mathrm{bp}$ of the cyt $b$ region for both northern and Amur pike. There were, respectively, 39 and 17 segregating sites in the cyt $b$ and D-loop region for northern pike. Nucleotide diversity for this species ranged from 0.0052 (D-loop) to 0.0031 (cyt b). The alignments of Amur pike showed 10 segregating sites for cyt $b$ and 3 for D-loop. The nucleotide diversity ranged from 0.0012 (D-loop) to 0.0020 (cyt $b$ ).

\section{Haplotype distribution}

The phylogenetic tree of concatenated D-loop and cyt $b$ sequences revealed 38 haplotypes, 28 in northern pike and 10 in Amur pike (Figure 1). The northern and Amur pike haplotypes each formed two strongly supported clades and the two species did not share any haplotypes. Thus, the minimum spanning network revealed two separate, unconnected clusters (Figure 2).

Three groups of northern pike sequences were detected in all analyses (Figures 1 and 2) and genetic differentiation among the three lineages ranged from 0.4-0.6\%. One lineage (seen for both markers) of northern pike consisted

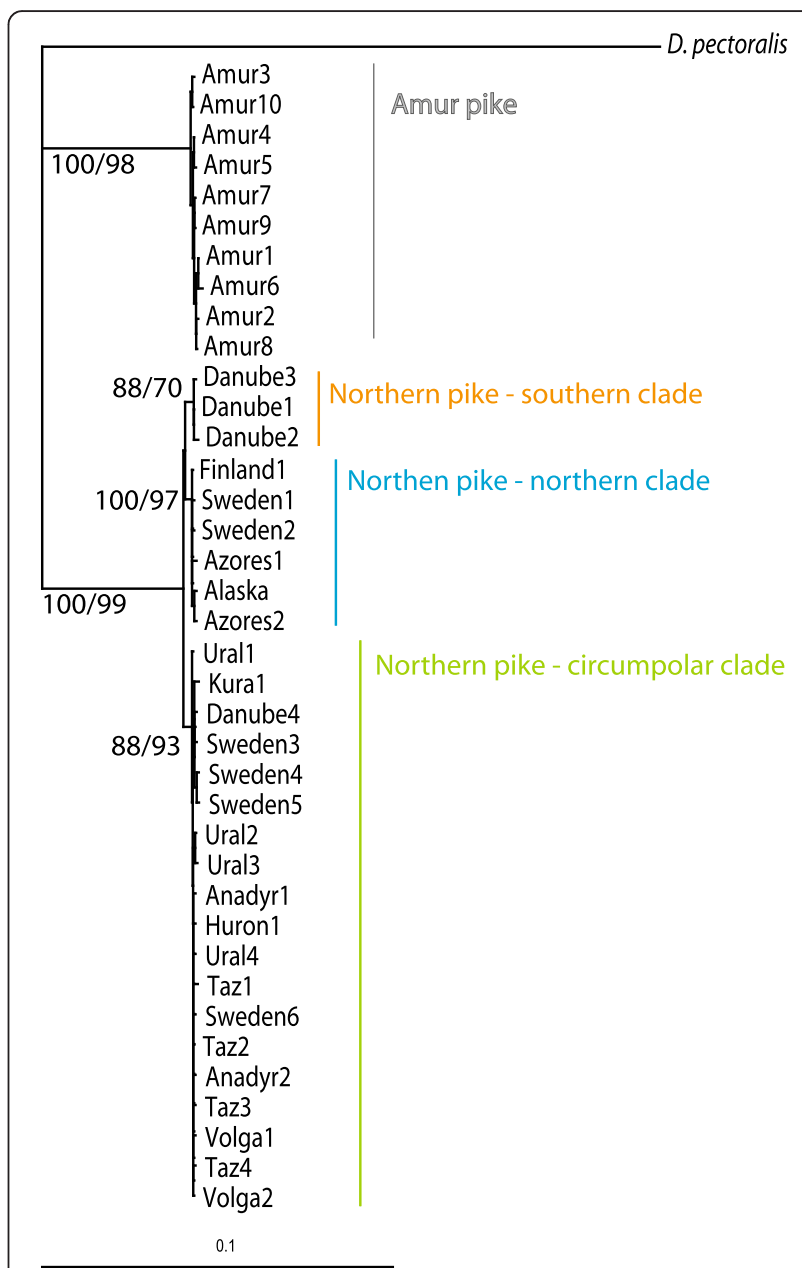

Figure 1 Phylogenetic relationship (Neighbour Joining topology) for the concatenated cyt $b$ and D-loop haplotypes of northern and Amur pike. Numbers on the branches indicate bootstrap support for NJ (10 000 replicates) and ML (100 replicates), respectively. Haplotype names are given on the basis of the river system or country of origin. The circumpolar haplotype group refers to circumpolar distribution of this clade of haplotypes. Note that the northern European clade harbours a haplotype originating from the Alaska population. 


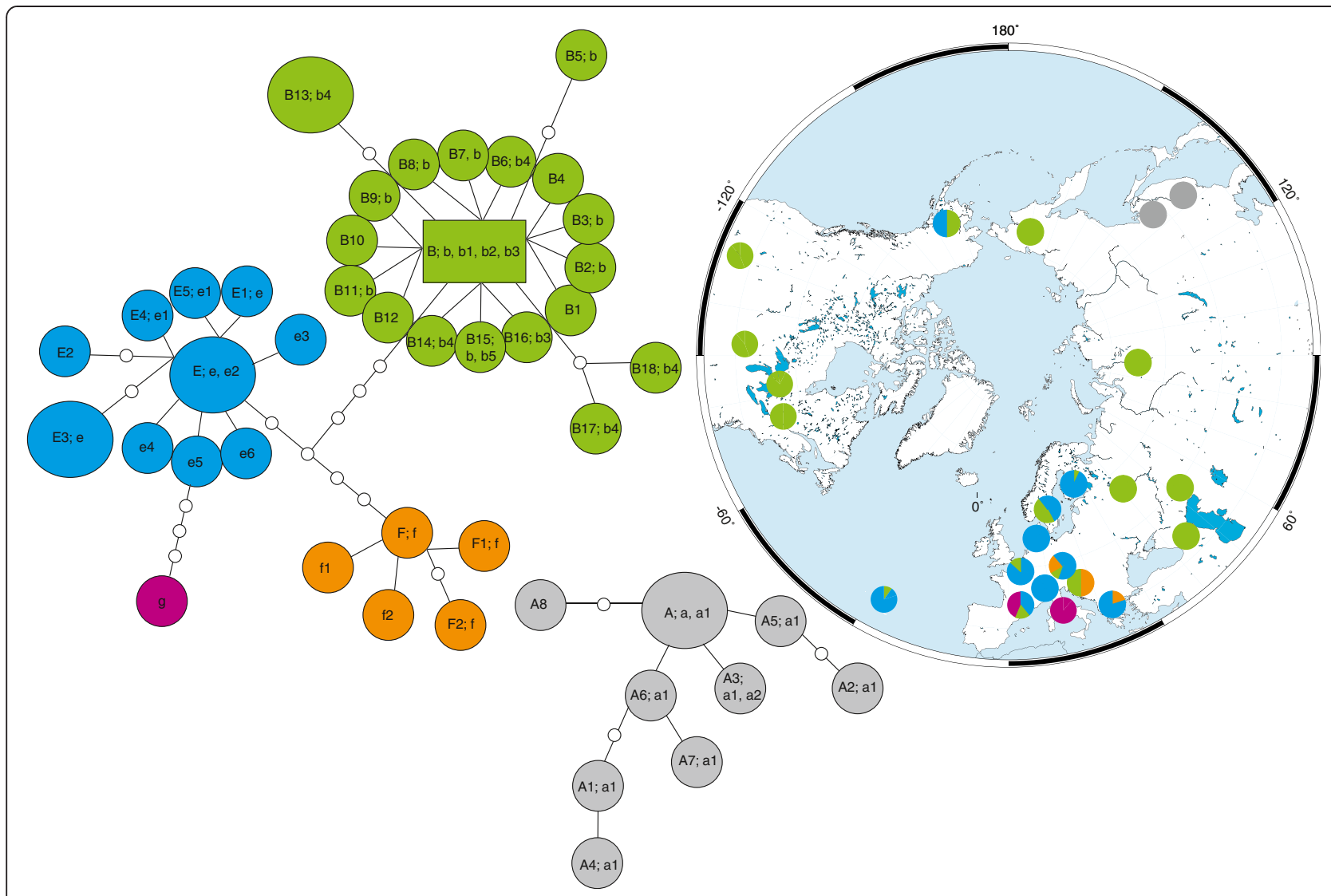

Figure 2 A minimum spanning network of the mtDNA haplotypes (cyt $b$ and D-loop) found in northern and Amur pike (grey). The cyt $b$ haplotypes are denoted by capital letters and numbers, and the D-loop haplotypes are denoted by lower-case letters and numbers (see Additional file 1). Geographic distribution of the haplogroups is displayed in the map. Amur pike haplotypes are indicated by grey circles.

of closely related haplotypes with a circumpolar distribution implying recent dispersal across the Holarctic (Figure 2, lineage B). Notably, within this lineage the same haplotype showed a Holarctic distribution as it could be detected in Europe, Asia and North America. Almost all populations of northern pike also displayed site-specific haplotypes (Additional file 1). The presence of site-specific haplotypes in most populations indicates limited present gene flow between northern pike populations inhabiting different freshwater bodies. The diversity of haplotypes was clearly larger in Eurasia than in North America, with clade $E(e)$ and $F(f)$ common in southern Europe. Further, a highly divergent haplotype (g) appeared in Mediterranean drainages (Italy, Switzerland; [25]). The Cyt $b$ haplotype diversity ( $\mathrm{Hd}$, Additional file 2) was slightly higher than the D-loop diversity.

\section{The split between Amur and northern pike}

The Amur - northern pike diversification was estimated to be $\sim 4.6 \mathrm{Myr}$ ago in the early Pliocene (Table 1 ). The further differentiation of the northern pike into the three different lineages was estimated to have taken place much later, 0.2-0.3 Myr ago (Table 1). There was no evidence for multiple lineages within the Amur pike (Figure 2).

\section{Historical demography}

The star pattern seen in the minimum spanning network for northern pike mtDNA haplotypes (Figure 2) may be a sign of potential recent population expansion, indicating that the haplotypes diverged simultaneously from a

Table 1 Time of divergence

\begin{tabular}{llllll}
\hline Comparison & $\mathbf{T}$ & $\begin{array}{l}\text { Time of } \\
\text { divergence * Myr }\end{array}$ & $\mathbf{P}$ & $\mathbf{T}$ & $\begin{array}{l}\text { Time of } \\
\text { divergence ** Myr }\end{array}$ \\
\hline $\begin{array}{l}\text { E. reichertii - } \\
\text { E. lucius }\end{array}$ & 103 & 4.55 & 0.53 & 6.7 & 4.73 \\
B - F & 5.9 & 0.26 & 0.32 & \\
B - E & 5.1 & 0.22 & 0.53 & \\
E - F & 4.1 & 0.18 & 0.28 & \\
\hline
\end{tabular}

Estimated time of divergence of E. reichertii and E. lucius, and clades of E. lucius, based on cyt $b$ data and the corresponding percentile value $(P)$, using a mutation rate $(\mu)$ of $1.133 \mathrm{E}^{-05}$ substitutions per year. $\mathrm{B}, \mathrm{E}$ and $\mathrm{F}$ denote the $E$. lucius cyt $b$ mt DNA lineages.

${ }^{*} \mathrm{~T}=2 \mu[62]$, ${ }^{* *} \mathrm{~T}=\mathrm{t}_{1} / \mathrm{N}_{\mathrm{ef}}[63]$. 
common ancestor. Analyses showed that all cyt $b$ lineages could recover the signal of sudden expansion - i.e.; none were significantly different from the expectation of sudden expansion (Table 2). However, additional tests (Tajima's D and Fu's F) were not consistent with historic expansion for the Danube population (the F-lineage in Figure 2). Estimated time of expansion for the Amur pike and the $B$ and $E$ lineages of the northern pike was around 0.1 Myr (Table 2). The estimated expansion of the $B$ and $E$ lineages was considerably later than the estimated split between these two lineages (0.22 Myr, Table 1). The overall time of expansion for the northern pike, based on cyt $b$, was $0.41 \mathrm{Myr}$ (Table 2).

\section{Discussion}

The circumpolar northern pike is monophyletic and clearly differentiated from the Amur pike. Based on the observed haplotype diversity in the northern pike we infer that present day distribution is due to expansion from three different glacial refugia. One lineage was found throughout the Holarctic suggesting dispersal from a common refugium, probably in Asia. An Eurasian origin of most of present day northern pike diversity is also supported by the higher overall diversity in Eurasia relative to Northern America.

\section{Amur pike - an old species with restricted distribution}

The northern pike and Amur pike haplotypes grouped as two monophyletic lineages with high support suggesting complete divergence (see Figure 1). A similar conclusion was also reached by Grande et al. [9]. We found no shared haplotypes between Amur pike and northern pike, and limited geographic structuring of haplotypes within Amur pike (Figure 2). Our data suggest that the Amur and northern pike split in the Pliocene (see Table 1). All Amur pike haplotypes formed a monophyletic group. The limited distribution of this species compared to northern pike may be explained by the mountain ranges Yablonovy and Stanovoy enclosing the Amur River and separating it from other eastern Siberian rivers [26].

Recently, two new species of pike were described from Italy - with a limited distribution somewhat parallel to that of the Amur pike. In two publications these species have been described as E. cisalpinus [5] and E. flaviae [4]. These species are with high probability the same, with a suggested vernacular name of southern pike [4]. The type locality of E. flaviae is Trasimeno [4], the same location where we have samples of northern pike belonging to the D-loop g clade [25]. Based on the minimum spanning network (Figure 2) the g clade is closely related to the e clade; the e clade has a wide distribution in Western Europe. The g clade seems to be present in drainages to the Mediterranean Sea, with related genotypes and phenotypes observed also in Switzerland and in the Danube $[4,25]$. Because of the limited data on the g clade, we could not estimate time of divergence. E. flavia is suggested to be a junior synonym of E. cisalpinus (see www.fishbase.org), and the distribution of the species is not clarified. More detailed genetic work is clearly needed to resolve the taxonomy of the European Esox.

Low levels of genetic diversity in northern and Amur pike The genetic diversity of the northern and Amur pike was low. Low levels of genetic diversity are expected for freshwater fishes at northern latitudes as a result of bottlenecks and reduced effective population sizes within refugia during glaciation periods [1]. Our data obtained from sequencing cyt $b(\pi=0.0031)$ and D-loop $(\pi=0.0052)$ for northern pike are in the low end of what has been reported for other freshwater fish species in northern latitudes $[1,21,22,27]$. The estimates are, however, in agreement with previous reports of low genetic variability in northern pike based on investigations of populations belonging to regions such as Europe and North America [16,24,25,28]. Here, we demonstrate that this is the case for the entire Holarctic distribution of pike.

Several reasons for low genetic variation in northern pike have been put forward, including low effective population size as is common for top predators [13], bottlenecks during glaciations in combination with subsequent founder effects during postglacial re-colonization [28], and restricted gene flow among populations [24,28]. The same arguments may hold for the Amur pike and other pike species. We used published $c y t b$ sequences for 10 muskellunge (E. masquinongy) individuals from Canada

Table 2 Estimated time of expansion

\begin{tabular}{lllllr}
\hline Comparison & $\mathbf{\tau}$ & Time of expansion Myr & $\mathbf{9 5 \%}$ Cl Myr & Tajima's D & Fu's F \\
\hline E. reichertii (A) & 2.5 & 0.11 & $0.13-0.18$ & -0.65 & -2.6 \\
E. lucius (B, E, F) & 9.2 & 0.41 & $0.01-4.20$ & -1.59 & -11.7 \\
B-lineage & 1.5 & 0.07 & $0.00-0.16$ & $-\mathbf{2 . 1 9}$ & -17.5 \\
E-lineage & 2.3 & 0.10 & $0.00-0.21$ & -0.82 & -10.6 \\
\hline
\end{tabular}

Estimated time of expansion based on cyt $b$ data and the corresponding $95 \%$ confidence intervals $(95 \% \mathrm{Cl})$, using a mutation rate ( $\mu$ ) of $1.133 \mathrm{E}-05$ substitutions per year. The cyt $b$ lineages representing $E$. reichertii $(A)$ and $E$. lucius (B, E, F), respectively are denoted in parenthesis. Significant values of Tajima's $D$ and Fu's $F$ are indicated in bold. 
and USA to compare level of genetic variation for the two related and similar species $[9,29]$. The estimated genetic variation for the muskellunge $(\pi=0.0078 \pm 0.0010)$ was larger than for the northern pike, but similar to what is observed for other freshwater fishes. This indicates that the top-predator hypothesis probably cannot explain the low level of genetic variation in northern and Amur pike.

We also detected a northern pike haplotype (Supplement 1 , cyt $b$ haplotype $\mathrm{B}$ and D-loop haplotype b) that was distributed throughout Eurasia and North America. Closely related haplotypes distributed across vast geographical areas (Europe, Asia and North-America) have also been shown for burbot (Lota lota) [30] and arctic charr (Salvelinus alpinus) [22]. Although such data are consistent with rapid postglacial expansions from a single refugium (for all three species) it is difficult to envision how such events - involving the Eurasian and the North American continents, could have taken place. Possibly, we are here facing ancient colonization processes at a point in time where the circumpolar distributed mtDNA haplotypes (for unknown reasons) were highly uniform.

\section{Geographic origins of the northern pike mtDNA lineages}

The phylogenetic tree of the concatenated cyt $b$ and Dloop haplotypes shows that the northern pike haplotypes are divided into three lineages. The northern pike phylogeny was not consistent with deep-branching clades indicating long-term reproductive isolation, which is usually caused by isolation in multiple refugia (see Figure 1). The three clades were also identified in the minimum spanning networks for the northern pike cyt $b$ and D-loop sequences (see Figure 2). Although the genetic differentiation among lineages was low $(0.4-0.6 \%$, ) compared to lineages traced to different refugia in other Holarctic freshwater fishes [21,30], the lineage distribution most likely point towards disjunctive refugia (see Figure 2), rejecting the suggestion of one single refugium for northern pike put forward by Maes et al. [24].

The localization of glacial refugia is often indicated by higher gene diversity in the refugial regions [20]. For the circumpolar distributed lineage (see Figure 2, B-lineage), the highest gene and nucleotide mtDNA diversities were found in the Ural River population. This river drains into the Caspian Sea, and the Ponto-Caspian region is a known and important aquatic refugium [1,31]. However, we cannot rule out the alternative possibility of a Beringian refugium for the circumpolar lineage, as the Anadyr River population also showed high diversity indices. Beringia has previously been implicated as a northern pike refugium by Bânârescu [26]. In addition, a glacial refugium in West Siberian ice lakes has been suggested for whitefish (Coregonus lavaretus) [32]; this might also possibly be a refugium for the northern pike B-lineage.
Two of the lineages primarily displayed a European distribution (see Figure 2, lineage $\mathrm{E}$ and F). The oldest and most diverse northern pike lineage is most likely the haplo-group found in the Danube watershed (the Flineage). The high diversity and restricted distribution indicates most probably presence of a refugium in this region. Two earlier studies on northern pike detected distinct branches connected to southern Europe in general [16,25], and one to Danube in specific [19]. Several studies on European freshwater fishes have shown that the Danube region was an important refugium during the Pleistocene glaciations $[21,26,30,31]$. However, recolonization of northern Europe by northern pike from this refugium seems improbable. The second European pike lineage might be derived from a central European refugium located between the northern and alpine ice caps as previously suggested [26,31]. A western European refugium is also suggested for other freshwater fish species [33-35]. However, the precise location of this refugium for northern pike is uncertain $[19,25]$. Notably, Scandinavia has probably been colonization from the central European refugium as well as from an eastern refugium by the circumpolar haplogroup, as also implied for the Eurasian perch (Perca fluviatilis) recolonization of Scandinavia [31,36]. Thus, northern Europe has most likely been recolonized from at least two different northern pike refugia and not one as earlier suggested [16,24].

\section{A recent circumpolar expansion of northern pike?}

The northern pike network revealed two star-like clusters of haplotypes, reflecting demographic expansions (Figure 2). Diversification events can often be attributed to a period of time when changes in the environment were particularly dramatic. Terminations of glacial periods are likely to be such events. The second glacial termination was initiated $130 \mathrm{kyr}$ ago [37], and both lineage B and $\mathrm{E}$ expanded around that time. A late Pleistocene Holarctic expansion has earlier been suggested for the northern pike [24], and our results support this for the circumpolar lineage. However, the total northern pike variation seen today cannot have accumulated after the last glaciation (ended $14 \mathrm{kyr}$ ago; [37]), as this would result in a divergence rate $(2 \mu=\tau / t)$ at $58 \%$ per Myr for the cyt $b$ region. In total, our data and analyses support the existence of multiple refugia for northern pike in the Holarctic during the last glaciation, followed by expansions from these refugia leading to separate star phylogenies.

\section{Conclusions}

The northern pike and the Amur pike did not share any haplotypes and are clearly differentiated taxa. The divergence time of the two taxa was estimated to $4.55 \mathrm{Myr}$. The northern pike showed three well-defined evolutionary lineages, each defined by a star phylogeny indicating 
population expansion following isolation in separate glacial refugia. One of these lineages has a present-day Holarctic distribution suggesting transcontinental dispersal from a single refugium. The observation of higher genetic diversity in Europe indicates that this lineage probably originated in Europe (east-Asia). Overall, there seems to be a need for further detailed phylogenetic studies of the genus Esox, particularly so for the Eurasian populations and species.

\section{Materials and methods}

\section{Populations sampled and use of existing GenBank data}

Samples from 24 northern pike populations representing a total of 12 drainages across the Holarctic, and three Amur pike populations from the Amur River were sequenced for variation in the mtDNA cytochrome $b$ (cyt $b$ ) and D-loop regions. In addition to the samples sequenced here, 12 cyt $b$ sequences (9 northern pike and 3 Amur pike) and $11 \mathrm{D}$ loop sequences (derived from altogether 108 European northern pike samples) were downloaded from GenBank (see $[9,25]$ for more sampling information). Sampling information and GenBank accession numbers are provided in Additional file 1.

\section{DNA extraction, amplification and sequencing}

DNA was isolated using chelex extraction [38]. The cyt $b$ region was amplified using the forward and the two reverse primers developed for esocid species by Grande et al. [9] according to the PCR protocol described therein - producing a PCR fragment of 1133 bp. A 443 bp fragment of the D-loop region was amplified using the primers CDL-D and PIDL and protocol described in [25]. The Anadyr samples of northern pike amplified poorly and only weak bands of the cyt $b$ region could be detected (using different annealing temperatures, concentrations of DNA, primer, dNTP and $\mathrm{MgCl}_{2}$ ). Due to a substantial level of heteroplasmy in both the Amur and northern pike all PCR products were subsequently cloned employing a TOPO-TA cloning kit (Invitrogen, Carlsbad, CA, USA). Five positive clones for each individual were then sequenced using M13 forward and reverse primers (Invitrogen, Carlsbad, CA, USA). Polymorphic sites detected in cloned products were verified by direct sequencing of PCR amplified clone inserts. For sites (single base) displaying heteroplasmy only the major variant was used in the subsequent analyses. DNA sequencing was performed with an ABI3730 system (Applied Biosystems, Foster City, USA) using the same primers for sequencing as in the PCRs. All sequences were aligned and visually inspected using the alignment explorer in MEGA 3.1 [39]. Sequences are available to GenBank (accession numbers KM281447-KM281494; Additional file 1).

\section{Genetic analyses}

Phylogenetic analyses were performed on the concatenated mtDNA alignments to assess whether we could detect distinct phylogenetic groups within the northern pike or Amur pike, and to investigate the relationship between these two species. This was done using maximum likelihood (ML) and distance (Neighbour-Joining, NJ [40]) phylogenetic methods as implemented in PAUP 4.0 [41] employing the model of evolution selected by Modeltest [42]. The optimal model selected by Akaike's information criterion [43] was an extended HKY model [44] including gamma distributed rates and rate variation across sites. Dallia pectoralis was used as outgroup based on the phylogenetic analysis done by López et al. [10,45]. Other Esox species ( $E$ niger and $E$ americanus) were also tested as outgroups and provided essentially the same topology. All PAUP and Modeltest analyses were performed at the Bioportal website at University of Oslo (htpp://www.bioportal. uio.no) The maximum likelihood analysis was done in PhyML [46].

Estimates of the net average divergence, $\mathrm{D}_{\mathrm{A}}$ [47] between sequences were calculated in MEGA 3.1 [39]. Standard errors were estimated by 10000 bootstrap replicates. Two different nucleotide diversity estimates were used; one based on the number of segregating sites (K) between the sequences, $\theta_{\mathrm{W}}=\mathrm{K} / \mathrm{a}[48]$ and another based on the amount of diversity ( $\Pi$ ) between two sequences, $\pi=\Pi / L$ [47]. For each phylogenetic lineage (supported by the bootstrap values), we calculated the nucleotide and haplotype diversity using DnaSP 4.0 [49].

We estimated the most parsimonious haplotype minimum spanning network (MSN) with $95 \%$ probability using the program TCS 1.21 [50]. Furthermore, a median-joining network (MJ) comprising both the northern pike and Amur pike haplotypes was constructed by the program NETWORK 4.2.0.1 (http://www.fluxus-engineering.com/ [51]). The northern pike haplotype networks created by the TCS program were nested by hand according to the rules of Templeton et al. [52] and Templeton and Sing [53] to reveal the grouping of haplotypes.

Both the haplotype networks and earlier reports [24] have indicated recent population expansion of northern pike. To test for this, we calculated the mismatch distribution of the different cyt $b$ phylogenetic lineages and compared the distributions to models of population expansion $[54,55]$. As more reliable mutation rate estimates are available for the coding cyt $b$ compared to non-coding D-loop, the mismatch distribution was calculated only for the cyt $b$ lineages, and not for the concatenated mtDNA or the D-loop dataset. For the expanding populations (defined by the mismatch distributions) we estimated the time of expansion ( $t$ ) using $\tau=2 \mu \mathrm{t}$, where $\tau$ (time to expansion) is estimated from the mismatch distribution and $\mu$ is the mutation 
rate. We assumed a $2 \%$ divergence rate per Myr in cyt $b$, based on published estimates of $2 \%$ in bony fishes [56], and 0.9-3.0 in freshwater fish [33,57,58]. Recent population expansion was also tested using Tajima's D [59] which utilizes the difference between $\pi$ and $\theta_{\mathrm{W}}$ (as defined above) to detect recent demographic changes (as these two parameters are differently affected by population bottlenecks and expansions). Population expansion was additionally tested using Fu's $F_{S}$ [60] which is particularly sensitive to population demographic expansion resulting in negative $F_{S}$-values. AMOVA, mismatch distribution, $\tau$, Tajima's $\mathrm{D}$ and Fu's $F_{S}$ were calculated using Arlequin v. 3 [61]. Confidence intervals were calculated by a parametric bootstrap approach as implemented in Arlequin v. 3.

We estimated divergence times between northern and Amur pike by the method of Gaggiotti and Excoffier [62] as implemented in Arlequin v. 3. This model assumes two populations diverging at time $\mathrm{T}$ and no further contact after time T. Furthermore, the size of the two populations may be different, but their sum equals the ancestral population size. The time of divergence (based on $\tau=2 \mathrm{~T} \mu$ ), the size of the ancestral population $\left(\theta_{0}=2 \mathrm{~N}_{0} \mu\right)$, and the relative population sizes of the two diverged populations are estimated, and their significance $\left(\mathrm{H}_{0}\right.$ : undifferentiated populations) tested by a permutation procedure. Divergence time was additionally calculated using MDIV [63], which estimates posterior distributions of divergence time $\left(T=t_{1} / N_{e f} ; t_{1}\right.$ is number of generations since divergence for the first ancestral population/species, whereas $\mathrm{N}_{\mathrm{ef}}$ is the effective population size of this first population/species), and other demographic parameters using MCMC. Both these methods for estimating divergence time scale the parameters by mutation rate $(\mu)$. Furthermore, they assume that population size does not change over time. The MDIV analyses were carried out using the resources of the Computational Biology Service Unit from Cornell University (http://cbsuapps.tc.cornell. edu/im.aspx) - partially funded by Microsoft Corporation.

\section{Additional files}

Additional file 1: Sampling of northern and Amur pike. Sampling drainage, geographic location, sample sizes, haplotype names and Genbank accession numbers are indicated.

Additional file 2: Diversity estimates. Gene diversity and nucleotide diversity for cytb and D-loop in the phylogeographic units identified (see Figure 2 and Additional file 1) in northern and Amur pike.

\section{Competing interests}

The authors declare that they have no competing interests.

\section{Authors' contributions}

AS, NCS and KSJ designed the study. AS and AK organised and analysed data. AS, KSJ and LAV wrote the paper and all authors read and approved the final manuscript

\section{Acknowledgements}

We would like to thank Mirjana Lenhardt, Howard Teas, Ed deLaplante, Bob Piorkowski, José Azevedo, Craig Primmer, Nikolay Shilin, Victor Stygar, Chingiz Mamedov, Sergei Shedko and the Svenska Fiskeriverket for providing samples, and Kjartan Østbye for thorough reading of the manuscript. We are also grateful to the ABI-sequencing team at CEES. This work was supported by a grant (159279/N40) from the Norwegian Research Council to KSJ and NCS.

\section{Author details}

${ }^{1}$ Centre for Ecological and Evolutionary Synthesis (CEES), Department of Biosciences, University of Oslo, P. O. Box 1066 Blindern, N-0316 Oslo, Norway. ${ }^{2}$ Cancer Registry of Norway, P.O. Box 5313 Majorstuen, N-0304 Oslo, Norway. ${ }^{3}$ Department of Ichthyology, Faculty of Biology, Moscow State University, Leninskie gory, 119991 Moscow, Russia.

Received: 13 June 2014 Accepted: 3 September 2014 Recelved. 13 June 2014 Accepted. 3 septem

\section{References}

1. Bernatchez L, Wilson CC: Comparative phylogeography of Nearctic and Palearctic fishes. Mol Ecol 1998, 7:431-452.

2. Hewitt GM: Some genetic consequences of ice ages, and their role in divergence and speciation. Biol J Linn Soc 1996, 58:247-276.

3. Costedoat C, Gilles A: Quaternary pattern of freshwater fishes in Europe: comparative phylogeography and conservation perspective. Open Cons Biol J 2009, 3:36-48.

4. Lucentini L, Puletti ME, Ricciolini C, Gigliarelli L, Fontaneto D, Lanfaloni L, Bilo F, Natali M, Panara F: Molecular and phenotypic evidence of a new species of genus Esox (Esocidae, Esociformes, Actinopterygii): the southern pike, Esox flaviae. PLoS ONE 2011, 6:12(12).

5. Bianco PG, Delmastro GB: Recenti Novità Tassonomiche Riguardanti Pesci D'acqua Doice Autoctoni in Italia e Descrizione di Una Muova Specie di Luccio. In Researches on Wildlife Conservation 2 (Supplement). Edited by de Filippo G. Italia: IGF Publishing; 2011:1-14.

6. Craig JF (Ed): Pike: Biology and Exploitation. London: Chapman \& Hall; 1996.

7. Wilson MVH, Brinkman DB, Neuman AG: Cretaceous Esocoidei (Teleostei): early radiation of the pikes in North American fresh waters. $J$ Paleontol 1992, 66:839-846.

8. Senanan W, Kapuscinski AR: Genetic relationships among populations of northern pike (Esox lucius). Can J Fish Aquat Sci 2000, 57:391-404.

9. Grande T, Laten H, Lopez JA: Phylogenetic relationships of extant esocid species (Teleostei: Salmoniformes) based on mophological and molecular characters. Copeia 2004, 2004:743-757.

10. Lopez JA, Chen WJ, Orti G: Esociform phylogeny. Copeia 2004, 3:449-464.

11. Hubbs CL, Lagler KF: Fishes of the Great Lakes Regions, revised edition. Ann Arbor, MI, USA: University of Michigan Press; 2004.

12. Healy JA, Mulcahy MF: A biochemical genetic analysis of populations of the northern pike, Esox lucius L., from Europe and North America. J Fish Biol 1980, 17:317-324.

13. Miller $L M$, Kapuscinski AR: Historical analysis of genetic variation reveals low effective population size in a northern pike (Esox lucius) population. Genetics 1997, 147:1249-1258.

14. Miller LM, Kapuscinski AR: Notes: microsatellite DNA markers reveal new jevels of genetic variation in northern pike. Trans Am Fish Soc 1996, 125:971-977.

15. Hansen MM, Taggart JB, Meldrup D: Development of new VNTR markers for pike and assessment of variability at di- and tetranucleotide repeat microsatellite loci. J Fish Biol 1999, 55:183-188.

16. Jacobsen BH, Hansen MM, Loeschcke V: Microsatellite DNA analysis of northern pike (Esox lucius L.) populations: insights into the genetic structure and demographic history of a genetically depauperate species. Biol J Linn Soc 2005, 84:91-101.

17. Laikre L, Miller LM, PalmÉ A, Palm S, Kapuscinski AR, Thoresson G, Ryman N Spatial genetic structure of northern pike (Esox lucius) in the Baltic Sea. Mol Ecol 2005, 14:1955-1964.

18. Larsen PF, Hansen MM, Nielsen EE, Jensen LF, Loeschcke V: Stocking impact and temporal stability of genetic composition in a brackish norther pike population (Esox lucius L.) assessed using microsatellite DNA analysis of historical and contemporary samples. Heredity 2005 , 95:136-143. 
19. Launey S, Morin J, Minery S, Laroche J: Microsatellite genetic variation reveals extensive introgression between wild and introduced stocks, and a new evolutionary unit in French pike Esox lucius L. J Fish Biol 2006 68:193-216.

20. Hewitt GM: Genetic consequences of climate oscillations in the Quarternary. Phil Trans R Soc Lond B 2004, 359:183-195.

21. Bernatchez $\mathrm{L}$ : The evolutionary history of brown trout (Salmo trutta L.) inferred from phylogeographic, nested clade, and mismatch analyses of mitochondrial DNA variation. Evolution 2001, 55:351-379.

22. Brunner PC, Douglas MR, Osinov A, Wilson CC, Bernatchez L: Holarctic phylogeography of Arctic charr (Salvelinus alpinus L.) inferred from mitochonrial DNA sequences. Evolution 2001, 55:573-586.

23. Jacobsen MW, Hansen MM, Orlando L, Bekkevold D, Bernatchez L, Willerslev E, Gilbert MTP: Mitogenome sequencing reveals shallow evolutionary histories and recent divergence time between morphologically and ecologically distinct European whitefish (Coregonus spp.). Mol Ecol 2012, 21(11):2727-2742.

24. Maes GE, van Houdt JKJ, de Charleroy D, Volckaert FAM: Indications for a recent Holarctic expansion of pike based on a preliminary study of mtDNA variation. J Fish Biol 2003, 63:254-259.

25. Nicod JC, Wang YZ, Excoffier L, Largiadèr CR: Low levels of mitochondrial DNA variation among central and southern European Esox lucius populations. J Fish Biol 2004, 64:1442-1449.

26. Bânârescu P: Distribution and Dispersal of Freshwater Animals in North America and Eurasia. Wiesbaden: Aula Verlag; 1992

27. Mäkinen HS, Merilä J: Mitochondrial DNA phylogeography of the threespined stickleback (Gasterosteus aculeatus) in Europe - evidence for multiple glacial refugia. Mol Phylogen Evol 2008, 46:167-182

28. Miller LM, Senanan W: A review of northern pike population genetics research and its implications for management. North Am J Fish Managem 2003, 23:297-306.

29. Kyle CJ, Wilson CC: Mitochondrial DNA identification of game and harvested freshwater fish species. Forensic Sci Int 2007, 166:68-76.

30. van Houdt JKJ, De Cleyn L, Perretti A, Volckaert FAM: A mitogenic view on the evolutionary history of the Holarctic freshwater gadoid, burbot (Lota lota). Mol Ecol 2005, 14:2445-2457.

31. Nesbø CL, Fossheim T, Vøllestad LA, Jakobsen KS: Genetic divergence and phylogeographic relationships among European perch (Perca fluviatilis) populations reflect glacial refugia and postglacial colonization. $\mathrm{Mol}$ Ecol 1999, 8:1387-1404

32. Østbye K, Bernatchez L, Næsje TF, Himberg KJM, Hindar K: Evolutionary history of the European whitefish Coregonus lavaretus (L.) species complex as inferred from mtDNA phylogeography and gill-raker numbers. Mol Ecol 2005, 14:4371-4387.

33. Kotlík P, Bogutskaya NG, Ekmekçi FG: Circum Black Sea phylogeography of Barbus freshwater fishes: divergence in the Pontic glacial refugium. Mol Ecol 2004, 13:87-95.

34. Volckaert FAM, Hanfling B, Hellemans B, Carvalho GR: Timing of the population dynamics of bullhead Cottus gobio (Teleostei : Cottidae) during the Pleistocene. J Evol Biol 2002, 15:930-944.

35. Cortey M, Vera M, Pla C, Garcia-Marin JL: Northern and Southern expansions of Atlantic brown trout (Salmo trutta) populations during the Pleistocene. Biol J Linn Soc 2009, 97:904-917.

36. Refseth UH, Nesbø CL, Stacy JE, Vøllestad LA, Fjeld E, Jakobsen KS: Genetic evidence for different migration routes of freshwater fish into Norway revealed by analysis of current perch (Perca fluviatilis) populations in Scandinavia. Mol Ecol 1998, 7:1015-1027.

37. Petit JR, Jouzel J, Raynaud D, Barkov NI, Barnola JM, Basile I, Bender M, Chappellaz J, Davis M, Delaygue G, Delmotte M, Kotlyakov VM, Legrand M, Lipenkov VY, Lorius C, PÉpin L, Ritz C, Saltzman E, Stievenard M: Climate and atmospheric history of the past 420,000 years from the Vostok ice core, Antarctica. Nature 1999, 399:429-436.

38. Walsh PS, Metzger DA, Higuchi R: Chelex-100 as a medium for simple extraction of dna for pcr-based typing from forensic material. BioTechniques 1991, 10:506-513.

39. Kumar S, Tamura K, Nei M: MEGA3: integrated software for molecular evolutionary genetics analysis and sequence alignment. Brief Bioinform 2004, 5:150-163.

40. Saitou N, Nei M: The neighbour-joining method - a new method for reconstructing phylogenetic trees. Jap J Gen 1986, 44:556-561.
41. Swofford DL: PAUP*. Phylogenetic Analysis Using Parsimony (*and Other Methods). Sunderland, MA: Sinauer Associates Inc.; 1998

42. Posada D, Crandall KA: Modeltest: testing the model of DNA substitution. Bioinformatics 1998, 14:817-818.

43. Akaike H: New look at statistical-model identification. IEEE T Automatic Contr 1974, AC19:176-723.

44. Hasegawa M, Kishino $H$, Yano TA: Dating of the human ape splitting by a molecular clock of mitochondrial-DNA. J Mol Evol 1985, 22:160-174.

45. Lopez JA, Bentzen P, Pietsch TW: Phylogenetic relationships of esocoid fishes (Teleostei) based on partial cytochrome $b$ and $16 \mathrm{~S}$ mitochondrial DNA sequences. Copeia 2000, 2:420-431.

46. Guindon S, Gascuel O: PhyML - a simple, fast, and accurate algorithm to estimate large phylogenies by maximum likelihood. Syst Biol 2003, 52:696-704

47. Nei M, Li W-H: Mathematical model for studying genetic variation in terms of restriction endonucleases. Proc Natl Acad Sci 1979, 76:2569-5273.

48. Watterson GA: On the number of segregating sites in genetical models without recombination. Theor Popul Biol 1975, 7:256-276.

49. Rozas J, Sánchez-DelBarrio JC, Messeguer X, Rozas R: DnaSP, DNA polymorphism analyses by the coalescent and other methods. Bioinformatics 2003, 19:2496-2497.

50. Clement M, Posada D, Crandall KA: TSC: a computer program to estimate gene genealogies. Mol Ecol 2000, 9:1657-1660.

51. Bandelt $\mathrm{H}-J$, Forster $P$, Röhl A: Median-joining networks for inferring intraspecific phylogenies. Mol Biol Evol 1999, 16:37-48

52. Tempelton AR, Boerwinkler E, Sing CF: A cladistic-analysis of phenotypic associations with haplotypes inferred from restriction endonuclease mapping. 1. Basic theory and an analysis of alcohol-dehydrogenease activity in Drosophila. Genetics 1987, 117:343-351.

53. Tempelton AR, Sing CF: A cladistic analysis of phenotypic associations with haplotypes inferred from restriction endonuclease mapping. 4. Nested analysis with cladogram uncertainty and recombination. Genetics 1993, 134:659-669.

54. Rogers AR, Harpending $\mathrm{H}$ : Population growth makes waves in the distribution of pairwise genetic differences. Mol Biol Evol 1992, 9:552-569.

55. Harpending $\mathrm{H}$ : Signature of ancient population growth in a low resolution mitochondrial DNA mismatch distribution. Hum Biol 1994 66:591-600

56. Bermingham EE, McCafferty S, Martin A: Fish biogeography and Molecular Clocks: Perspectives from the Panamanian Isthmus. In Molecular Systematics of Fishes. Edited by Kocher T, Stepien C. San Diego, California: Academic Press; 1997:113-128.

57. van Houdt JKJ, Hellermans B, Volckaert FAM: Phylogenetic relationships among Palearctic and Nearctic burbut (Lota lota): Pleistocene extinctions and recolonizations. Mol Phylogen Evol 2003, 29:599-612.

58. Bohlen J, Slechtova V, Bogutskaya N, Frejhof J: Across Siberia and over Europe: Phylogenetic relationships of the freshwater fish genus Rhodeus in Europe and the phylogenetic position of $R$. sericeus from the River Amur. Mol Phylogen Evol 2006, 40:856-865.

59. Tajima F: Statistical-method for testing the neutral mutation hypothesis by DNA polymorphism. Genetics 1989, 123:585-595.

60. Fu Y-X: Statistical tests of neutrality of mutations against population growth, hitchhiking and background selection. Genetics 1997, 147:915-925.

61. Excoffier L, Laval G, Schneider S: Arlequin ver. 3.0: an integrated software package for population genetics data analysis. Evol Bioinforma 2005, 1:47-50.

62. Gaggiotti OE, Excoffier L: A simple method of removing the effect of a bottleneck and unequal population sizes on pairwise genetic distances. Proc R Soc B 2000, 267:81-87.

63. Nielsen $\mathrm{R}$, Wakeley J: Distinguishing migration from isolation: a Markov chain Monte Carlo approach. Genetics 2001, 158:885-896.

doi:10.1186/s12983-014-0067-8

Cite this article as: Skog et al:: Circumpolar phylogeography of the northern pike (Esox lucius) and its relationship to the Amur pike (E. reichertii). Frontiers in Zoology 2014 11:67. 